\title{
Automatic Packaging Machine
}

\section{Prof. S. B. Mandlik, Patole Abhishek, Alase Aishwarya, Modhe Anuja}

Department of Electronics and Telecommunication Engineering, Pravara Rural Engineering college, Loni, India

\section{ABSTRACT}

Article Info

Volume 8, Issue 3

Page Number: 342-347

\section{Publication Issue :}

May-June-2021

\section{Article History}

Accepted : 01 June 2021

Published: 05 June 2021
Many small scale food production business owners and small and medium scale Grocery Store owners do the process of weighing and packaging their product manually. Small and Medium scale food production business owners has to do the weighing, filling and packaging process manually. The sealing process is carried out with the help of candles. This process is very time and effort consuming and thus it limits their production as well as their business. Automatic Weighing and Packaging which is priced at the rate mentioned is not affordable for small scale and medium scale businesses. This project aims to develop such a machine which automatically weighs and packs the food with the help of microcontroller and sensors. The idea is to manually place the bag, then automatic weighing, filling and packaging is done. The purpose of doing this project is to reduce human efforts and time consumption. Decreasing machine cost is the major advantage of project. The machine design is based on simple mechanisms and it can be installed easily. The speed of packaging is increased thus resulting in more production and business. It will eradicate the traditional packing and sealing method. This process will reduce the number of paid workers.

Keywords : Automatic Packaging, Arduino Uno, Conveyor Belt, Servo Motor, LCD display, Load Cell.

\section{INTRODUCTION}

Industry automation becomes the global trend in manufacturing, packaging process is one of the most uses in industry; more and more companies are switching to automation. This project is devoted to the use of automatic control system in process machine system; the control system will play a major role in control on all parts of the project. This project report is about design and fabricates an automated packaging machine system. Electrical DC motors control were used as actuators for the entire process to move the upper and lower conveyor belts, and the sensors used to feed the control system by system information. Conveyor belt is use for transporting samples from one location to another which would be packaged into a specific paper boxes later. The control system for the hardware project is to be controlled by the Arduino. The main purpose of this project was to provide the small sector food industry (MSME) with a platform that they are able to process their food item in safe packets by reducing the cost of packaging 
machines. In comparison with the large OEMS who have multi brand packing system show case their nutritional value of their products and additional information regarding show case and other information, which provide them a great source and huge marketing opportunity in business and customer satisfaction. We did it through designing the whole machine in virtual environment (solid works) where every component was based on standard available mainly electronic part for automation (semi automation). Weight checking was removed by adding volumetric cup filler according to product packaging of particular industry. The design and simulation were based on the company layout factory area where we took it on virtual environment and simulated it. The synchronization of machine was done according to the controller employed in the control of machine for sealing of the packets of food items. Arduino based automation system was employed for automation.

The automatic weighing and packaging machines provide a wide array of applications for different industries. The greatest asset of the packaging and weighing machines that are manufactured in the market is that they are advanced and they provide effective coordination with the other processes of production in the best possible manner. It is important for the food industry to stick to the market standards in a position that will make sure their brand value and also attach to the industry quality standards in the best possible manner. It is necessary to note that the customized solutions provided by packing machines for food products in India are modified today to meet a particular set of items in the process

\section{LITRATURE SURVEY}

Tawanda Mushiri and Charles Mbohwa Johannesburg, South Africa [1], filed September 1011, 2015 titled as 'Design of a small scale cereal packaging machine suitable for developing countries'. More particularly, this invention concerns creating a small scale cereal packaging machine which has capability of sealing $1 \mathrm{~kg}$ of any cereal per minute. The invention has particular application to automatic weighing and packaging and sealing using cheaper and more efficient alternative of food packaging machinery.

"Automatic Packing Machine": This invention contemplates is the introduction of simple pneumatic, hydraulic, mechanical and electrical devices into the existing production machinery, with a view to improving their productivity. The working principle of the invention is as followed: Products are passed on conveyor. They are sensed by the first proximity sensor and the counter is set to ' 1 '. As soon as the product completely passes through the sensor, SENSOR 1 switches off. When the sensor switches off, timer (previously set to certain delay) starts.

Melchizedek Alipio, Angelo A. Beltran Jr., De La Salle University, Manila, Philippines [3] titled as 'Automation of Packaging and Material Handling Using Programmable Logic Controller'. This paper presents an automation of packaging and material handling using a programmable logic controller. The idea is to automate the process of placing the materials inside a box, detecting good and bad items in terms of weight, and sealing using a packaging tape. The purpose of the study is to replace the manual system being used in the Industry, compare the time, and manpower requirement for both the existing system with the proposed automated system. The Mitsubishi FX series programmable logic controller is used to mechanize the system. Sensors such as proximity and load sensor are used to provide the input to the system. The motors, pneumatics, and also the solenoids serve as the output.

Mr. Abhishek Shigwan, Mr. Pankaj Shirke, Ms. Snehal Ukarde, Ms. Priyanka Salaskar, Mr. Guru Bhurshe, Mumbai [4] titled as 'Automatic Packing Control Machine'. The idea is to automate the process 
of placing the material on the paper sheet, detecting items and folding simple mechanism. The purpose of doing this project is to reduce human effort. Decreasing machine cost is also advantages of our design. This machine design is based on simple mechanism and can easily install. It is found out that the system decreases time and manpower requirements for every station as compared with traditional manual system.

M. R. Saraf, V. V. Ruiwale, V. V. Kulkarni and S. M. Kulkarni titled as 'Design and Development of Cost Effective Automatic Machine for Powder Packaging'[5] In the design shown above, a separate weighing mechanism is added. Load cell arrangement allows for accurate measurement of the material to be filled in the pouch. Load cell arrangement allows for accurate measurement of the material to be filled in the pouch.

\section{PROPOSED WORK}

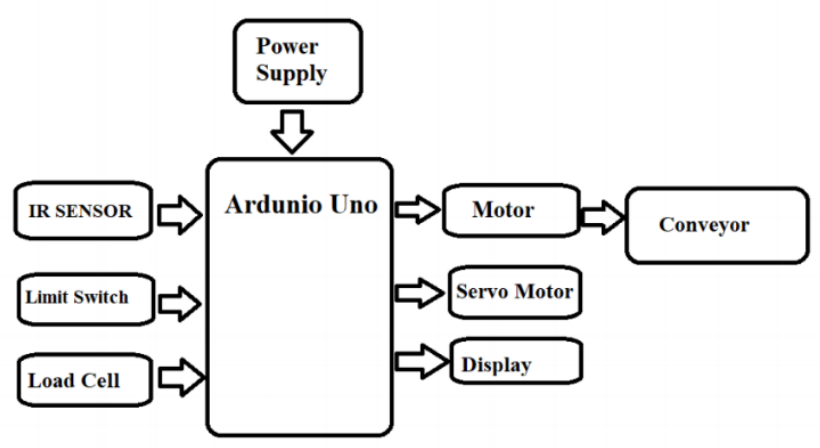

Figure 1: Block Diagram

We developed automation technique using Arduino Board and increase the speed and accuracy of the process of production. We used one load cell for measuring the weight of product before packaging and displayed the weight of product using LCD. Arduino uno board has inbuilt power supply here we have to interfacing for load cell and LCD. This is the initial step of the hardware and then conveyor belt motor and servo motor we have to control according to input ofsensor.

\section{A. Arduino uno}

A micro-controller (noun) is a small computer on a single integrated circuit containing a processor core, memory, and programmable input/output peripherals. The Arduino Uno is a microcontroller board based on the ATmega328. It has 14 digital input/output pins (of which 6 can be used as PWM outputs), 6 analog inputs, a $16 \mathrm{MHz}$ crystal oscillator, a USB connection, a power jack, an ICSP header, and a reset button. Arduino uses its own IDE (Integrated Development Environment) uses as amplified version of $\mathrm{C}++$, making it easier to learn to program.

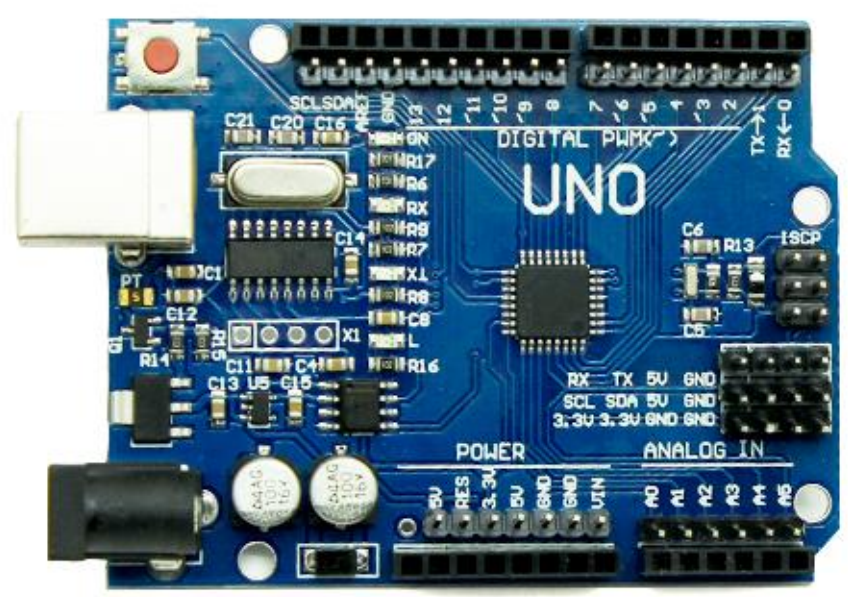

Figure 2: Aruino Uno

\section{B. Load Cell}

A load cell is a sensor that converts a load or force or weight acting on it into an electronic signal. This electronic signal can be a current change, voltage change or Frequency change depending on the type of load cell and circuit used. Principle of piezo-resistivity is used in load sensors. When a load or force or stress is applied to the sensor, the resistance is changed. Resistance change causes change in output voltage when an input voltage is applied. Strain gauge load cells are most commonly in weighing and packaging industry. These load cells are particularly inflexible, have very good echo values, and have longer life cycles in application. Strain gauge load cells work on 
the principle that the strain gauge (a planar resistor) deforms when the material of the load cells deforms appropriately. Electrical resistance is changed by the deformation of strain gauge, by an amount that is proportional to the strain. The change in resistance of the strain gauge provides an electrical value change that is enumerated to the load placed on the load cell

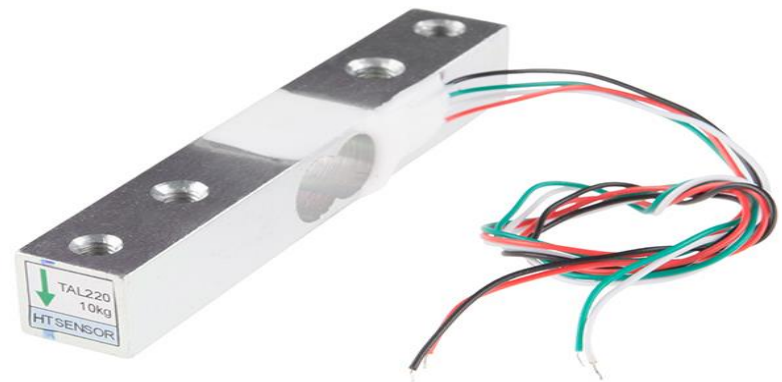

Figure 3: Load cell

\section{Conveyor Belt:}

Elementary conveyor belts were used since the 19th century. In 1892, Thomas Robins began a series of inventions relating to conveyor systems, which led to the development of a conveyor belt used for carrying coal, ores and other products. Now a day's Conveyor belt system are widely used in cement industries, power plant, food industries, production industries etc. So it is essential equipment for in house material transportation today. The modification and latest technologies or methodologies used in different applications to reduce failures, maintenance cost and equipment related a fatal accident occurs during operation [1]. In our design Conveying system is a way through which passing products by using conveyor belt.

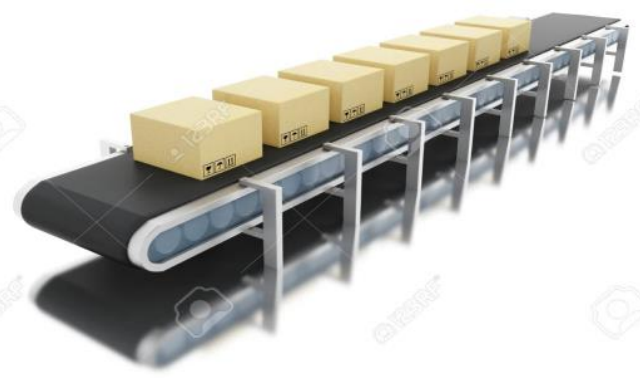

Figure 4: Conveyor Belt

\section{LCD Display:}

A 16x2 LCD means it can display 16 characters per line and there are 2 such lines. In this LCD each character is displayed in $5 \times 7$ pixel matrix. This LCD has two registers, namely, Command and Data. The command register stores the command instructions given to the LCD. A command is an instruction given to LCD to do a predefined task like initializing it, clearing its screen, setting the cursor position, controlling display etc. The data register stores the data to be displayed on the LCD.

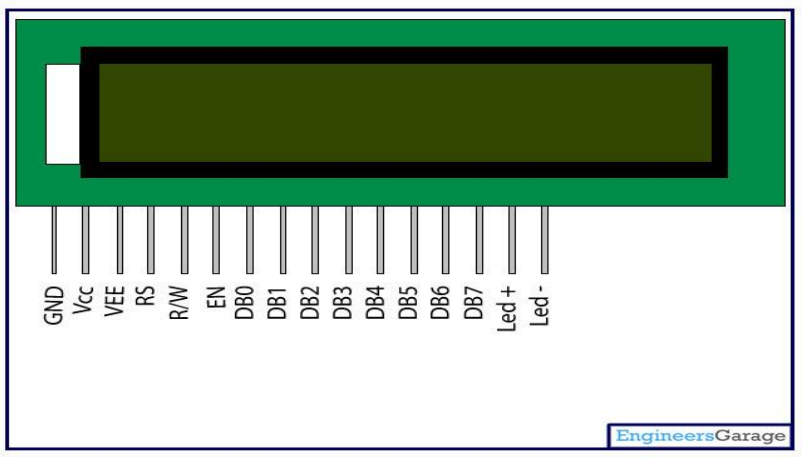

Figure 5: Relay Driver Circuit

\section{E. IR Sensor}

Proximity Sensor is used to detect objects and obstacles in front of sensor. Sensor keeps transmitting infrared light and when any object comes near, it is detected by the sensor by monitoring the reflected light from the object. It can be used in robots for obstacle avoidance, for automatic doors, for parking 
aid devices or for security alarm systems, or contact less tachometer by measuring RPM of rotation objects like fan blades.

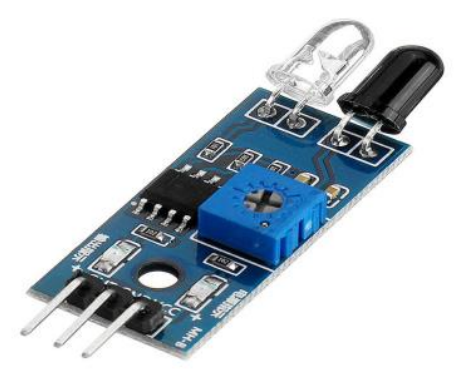

Figure 6: IR sensor

\section{F. Servo Motor}

A servo motor is a type of motor that can rotate with great precision. Normally this type of motor consists of a control circuit that provides feedback on the current position of the motor shaft; this feedback allows the servo motors to rotate with great precision. If you want to rotate an object at some specific angles or distance, then you use a servo motor. It is just made up of a simple motor which runs through a servo mechanism.

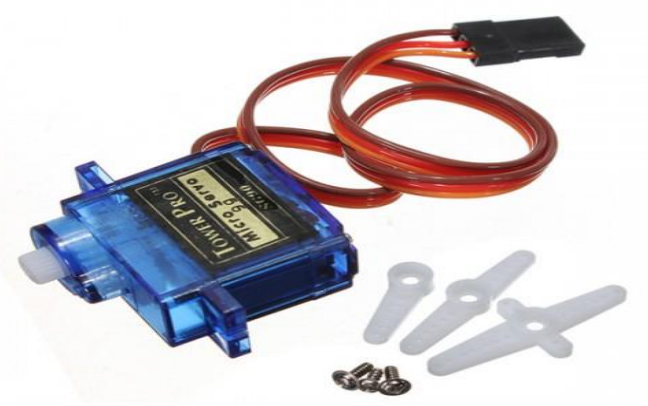

Figure 7: Servo Motor

\section{CONCLUSION}

In industry the production speed should be high because the demand of the product is more. But when we check weight of the object manually then it will take more time for checking the weight and overall speed the production will decrease. So by using this auto weighing and packaging system we totally overcome this problem by Arduino, Conveyor Belt will handled all the operation regarding the weight, timing of the job. he packaging and material handling will be a fully automated process without any human intervention. his can be helpful in other industries too, resulting in safe operating system, efficient packaging, fast response time and less number of workers.

\section{REFERENCES}

[1]. Tawanda Mushiri, Charles Mbohwa, International Conference on Operations Excellence and Service Engineering Orlando, Florida, USA, September 10-11, 2015.

[2]. Shashank Lingappa M., Vijayavithal Bongale, Sreerajendra, International Journal of Advanced Mechanical Engineering.ISSN 2250-3234 Volume 4, Number 7 (2014), pp. 803-811

[3]. Melchizedek Alipio, Angelo A. Beltran Jr., International Journal of Scientific Engineering and Technology (ISSN: 2277 -1581), Volume No. 3, Issue No. 6, pp: 767 -770. 1 June 2014

[4]. Mr. Abhishek Shigwan, Mr. Pankaj Shirke, Ms. Snehal Ukarde, Ms. Priyanka Salaskar, Mr. Guru Bhurshe, IJSRD - International Journal for Scientific Research \& Development| Vol. 4, Issue 02, 2016 | ISSN (online): 2321-0613

[5]. M. R. Saraf, V. V. Ruiwale, V. V. Kulkarni and S. M. Kulkarni, International Journal of Current Engineering and Technology (E-ISSN 2277 4106, P-ISSN 2347 - 5161), Special Issue-4 (March 2016) 
[6]. Alhade A. Algitta, Mustafa S., Ibrahim F., Abdalruof N. and Yousef M., titled as 'Automated Packaging Machine Using PLC' IJISET - International Journal of Innovative Science, Engineering \& Technology, (ISSN 2348 - 7968) Vol. 2 Issue 5, May 2015

[7]. Said Elshahat Abdallah and Wael Mohamed Elmessery, titled as 'an innovative low-cost automatic prototype for fruits and vegetables weight basis packaging', Misr J. Ag. Eng., 35 (1): 169 - 198, January 2018

\section{Cite this article as :}

Prof. S. B. Mandlik, Patole Abhishek, Alase Aishwarya, Modhe Anuja, "Automatic Packaging Machine", International Journal of Scientific Research in Science, Engineering and Technology (IJSRSET), Online ISSN : 2394-4099, Print ISSN : 2395-1990, Volume 8 Issue 3, pp. 342-347, May-June 2021. Available

doi : https://doi.org/10.32628/IJSRSET218349

Journal URL : https://ijsrset.com/IJSRSET218349 